\title{
Cases of asphyxia in children and adolescents: a retrospective analysis of fatal accidents, suicides, and homicides from 1998 to 2017 in Hamburg, Germany
}

\author{
Dieu Phuong Mosek ${ }^{1}$ - Jan Peter Sperhake ${ }^{2} \cdot$ Carolin Edler $^{2} \cdot$ Klaus Püschel $^{2}$ • Ann Sophie Schröder ${ }^{2}$
}

Received: 27 September 2019 / Accepted: 8 January 2020 / Published online: 18 January 2020

(C) The Author(s) 2020

\begin{abstract}
Purpose Injury-related asphyxia is one of the most common causes of death in children in Germany. However, only a few systematic studies have analyzed the causes and circumstances of asphyxia in children and adolescents.

Methods All cases of asphyxia in children and adolescents (0-21 years of age) among the Hamburg Legal Medical Department's autopsy cases from 1998 to 2017 were retrospectively analyzed with special focus on how often external findings were completely absent.

Results Among 249 cases of fatal asphyxia, $68 \%$ were accidents, $14 \%$ were suicides, and $13 \%$ were homicides. Most of the cases involved boys. Adolescents and young adults aged 15-21 years represented the main age group. Drowning was the leading mechanism of asphyxia. Younger age was associated with less frequent detection of external signs of asphyxia in the postmortem external examination. Petechial hemorrhages were the most common visible external indication of asphyxia. No external findings indicative of asphyxia were present in $14 \%$ of the cases.

Conclusion Asphyxia in children and adolescents often involves accidents. However, postmortem external examination alone is insufficient to identify asphyxia and the manner of death.
\end{abstract}

Keywords Asphyxia $\cdot$ Childhood deaths $\cdot$ Cause of death $\cdot$ Manner of death $\cdot$ Autopsy

Selected classifications

10: Forensics

10.010: Pathology

10.020: Medicine

10.030: Sciene

10.140: Crime Scene

Key points - Two-thirds of the asphyxia-related deaths were accidentrelated; occurring with almost equal frequency during day and night.

- Most of the incidents occurred at home (exception: cases of drowning).

- Suicides began occurring at 9 years of age with hanging as the most common method.

- External findings of asphyxia were not evident in $14 \%$ of the cases, occurring more frequently in younger children.

- The most common external indication of asphyxia was petechial hemorrhages.

Ann Sophie Schröder

as.schroeder@uke.de

1 Department of Internal Medicine, Wilhelmsburger Hospital Groß-Sand, Groß-Sand 3, 21107 Hamburg, Germany

2 Department of Legal Medicine, University Medical Center Hamburg-Eppendorf, Butenfeld 34, 22529 Hamburg, Germany

\section{Introduction}

Asphyxia is the generic term for mechanisms that cause a deficiency of the tissue oxygen supply that is required to sustain metabolic function [1]. The four physiological causes of asphyxia are reduced oxygen in the environment, reduced blood oxygenation, reduced cardiovascular oxygen transfer, and interference with cellular oxygen absorption [2].

In the forensic context, the mechanisms of asphyxia include mechanical causes, such as strangulation, aspiration of foreign bodies or boluses, or constriction; changes in breathable air, such as flue gas inhalation; strangulation mechanisms, such as hanging or ligature strangulation; positional asphyxia; and drowning [3].

Asphyxia and acts of violence are the leading injury-related causes of death in children under 15 years of age in Germany [4]. Previous studies have primarily examined accidental deaths caused by asphyxia; few data are available on the specific distribution of deaths according to the causes of asphyxia [5]. The medicolegal specialist plays a particularly important role in preventing these cases of death by reconstructing the 
circumstances of death, analyzing the injury patterns, and identifying potential sources of danger [6].

Postmortem external examination alone does not reliably identify asphyxia. Indications of asphyxia, such as petechial hemorrhages or findings of injury that suggest the asphyxia mechanism, may be completely missing and/or misinterpreted by non-specialist postmortem examination physicians. An autopsy to clarify the cause of death should be performed in all suspicious cases despite the fact that a precise cause of death cannot be determined by autopsy in all cases. Diagnosing asphyxia in infants and small children is particularly difficult because violent death in children may leave almost no visible traces [2]. Particularly challenging is differentiating between death by asphyxia and sudden infant death syndrome (SIDS); such differentiation is not always possible [7].

The present study was a systematic overview of all cases of asphyxia in children, adolescents, and young adults in a German metropolitan area that involved a medicolegal autopsy between 1998 and 2017. Our findings present the spectrum of different mechanisms of asphyxia and the circumstances of death in various age groups, and the rates of diagnosis of asphyxia during the postmortem external examination.

\section{Materials and methods}

All autopsies performed at the Department of Legal Medicine (Institut für Rechtsmedizin, IfR) of the University Medical Center Hamburg-Eppendorf from 1 January 1998 to 31 December 2017 were retrospectively analyzed. Cases in which the postmortem medical examiner had considered all circumstances for the diagnosis of fatal asphyxia in children, adolescents, or young adults aged $0-21$ years were included in the study.

The available documents were descriptively analyzed regarding the circumstances of death, mechanisms of asphyxia, pre-existing medical conditions, hospital treatments, resuscitation, time and place of occurrence, presence of a chaperone, age, sex, and presence of asphyxia findings during the postmortem external examination. Microsoft Excel (Microsoft Corp., Redmond, WA, USA) was used for data input and analysis.

\section{Results}

The IfR performed 23,638 autopsies from 1998 to 2017. Death caused by asphyxia was identified in 249 autopsies (1\% of all autopsies; 242 medicolegal autopsies and 7 private autopsies) in children and adolescents (021 years of age).

\section{Circumstances of death (accident, suicide, or homicide)}

Table 1 shows the circumstances of death (accident, suicide, or homicide) according to age group. Most cases involved accidents (more than half of the cases of death in all age groups). Suicides and homicides occurred with almost equal frequency. Suicides occurred in only one case at the age of 9 years and then in all ages from 12 to 21 years of age. The most common suicide mechanism was hanging. Homicides occurred most often in newborns.

\section{Mechanisms of asphyxia}

Table 2 shows the distributions of age and sex among the asphyxia mechanisms, which are divided into drowning, gas inhalation, aspiration of endogenous fluids, aspiration of foreign objects, smothering of the respiratory tract, suffocation during birth, positional asphyxia and constriction, hanging, manual strangulation, ligature strangulation, other strangulation mechanisms, and combined mechanisms of asphyxia. Two-thirds of the cases of death caused by asphyxia involved boys, most of whom had died from accidents. Girls were more often the victims of homicides.

\section{Pre-existing medical conditions, hospital treatment, and resuscitation}

Fifty-four cases $(22 \%)$ had experienced a chronic medical condition and 22 (9\%) had experienced an acute medical condition. Six cases $(2 \%)$ had undergone a surgical intervention within the previous 2 weeks.

Additionally, a hospital treatment was administered following the incident in 39 cases (16\%). Medical personnel had performed resuscitation in 95 cases (38\%).

\section{Time of occurrence}

In total, 116 (47\%) cases of asphyxia had occurred during the night (6:00 PM-6:00 AM), 89 (36\%) had occurred during the day (6:00 AM-6:00 PM), and the time of occurrence remained unknown in 44 cases (17\%). Accidents had occurred almost equally during the day and night.

\section{Place of occurrence}

A total of $128(51 \%)$ cases of asphyxia had occurred at home, $95(38 \%)$ in public, $13(5 \%)$ in care facilities, and $9(4 \%)$ in hospitals. The home of the offender had been the place of occurrence in two cases $(1 \%)$, and the place of occurrence remained unknown in two cases $(1 \%)$. 
Table 1 Circumstances of death (accident, suicide, or homicide) according to age group

\begin{tabular}{lccccr}
\hline Age groups & Accident & Suicide & Homicide & Unclear & Total \\
\hline Newborns (0-4 weeks) & $13(68 \%)$ & $0(0 \%)$ & $6(32 \%)$ & $0(0 \%)$ & 19 \\
Infants (>4 weeks-1 year) & $15(71 \%)$ & $0(0 \%)$ & $2(10 \%)$ & $4(19 \%)$ & 21 \\
Toddlers (1-4 years) & $46(88 \%)$ & $0(0 \%)$ & $5(10 \%)$ & $1(2 \%)$ & 52 \\
Schoolchildren (5-14 years) & $36(64 \%)$ & $6(11 \%)$ & $9(16 \%)$ & $5(9 \%)$ & 56 \\
Adolescents and young adults (15-21 years) & $58(57 \%)$ & $30(30 \%)$ & $10(10 \%)$ & $3(3 \%)$ & 101 \\
Total & $168(68 \%)$ & $36(14 \%)$ & $32(13 \%)$ & $13(5 \%)$ & 249 \\
\hline
\end{tabular}

\section{Chaperone}

A chaperone had either been in the same building or within shouting distance in 132 cases (53\%). The chaperone was either an adult family member or supervising staff of the respective institution (teacher, childcare worker, nursing staff, or correctional facility staff). Thus, the chaperone was also the offender in homicides. In 107 cases (43\%), the incident had occurred without a chaperone close by. The presence of a chaperone could not be ascertained in 10 cases (4\%). A chaperone had been present in close proximity in 97 (58\%) accident-related cases of death and not in close proximity in 64 cases (38\%). A chaperone had been in the same building or within shouting distance in 11 of the suicide cases (31\%).

\section{Findings of asphyxia in the postmortem external examination}

Neither external indications of asphyxia (e.g., petechial hemorrhages, facial edema, or cyanosis) nor the mechanism of asphyxia (e.g., spotty, recessed livor mortis; injuries; or hematomas) were identified in 35 cases (14\%) (Table 3). Fewer indications of asphyxia were found during the postmortem external examinations of younger children. Petechial hemorrhages were present in 92 cases (37\%): in 46 cases (27\%) of accidents, 18 cases $(50 \%)$ of suicides, 23 cases $(72 \%)$ of homicides, and in 5 cases (38\%) of the deaths where the circumstance of death remained unclear. Petechial hemorrhages were found in $32(34 \%)$ cases with cardiopulmonary resuscitation (CPR) and in 60 (39\%) cases without CPR (Table 4).

\section{Drowning}

The leading mechanism of asphyxia was drowning ( 82 cases, $33 \%$ ). The most prevalent ages among cases of drowning were 1, 2, 16, and 21 years (Fig. 1).

A chaperone had been present in 32 cases (39\%). Twentythree children $(28 \%)$ had known how to swim, $34(41 \%)$ had been non-swimmers, and no information was available in 24 cases $(29 \%)$. Most cases of drowning occurred in public bodies of water (64 cases, 78\%). The postmortem external examination revealed indications of drowning in 71 cases $(87 \%)$, and a "mushroom of foam" adjacent to the mouth and nose was present in 14 cases $(17 \%)$.

\section{Gas inhalation}

Gas inhalation was the mechanism of asphyxia in 35 cases (14\%). There was one case of hydrogen sulfite intoxication; all other cases involved carbon monoxide intoxication. The postmortem external examination showed clear indications of gas inhalation in 34 cases (97\%). Light red livor mortis and airway soot deposition were the most common findings, identified in 29 cases $(83 \%)$.

\section{Aspiration of endogenous fluids}

Aspiration of endogenous fluids was the mechanism of asphyxia in 35 cases (14\%). The injuries sustained in two homicides and four suicides resulted in aspiration of blood. Twenty cases (57\%) had occurred at night and $18(51 \%)$ had occurred at home. A chaperone had been present in 19 cases (54\%). Almost half of the aspiration-related cases of death (16 cases, $46 \%$ ) involved individuals with pre-existing medical conditions. The postmortem external examination showed indications of asphyxia in 29 cases $(83 \%)$.

\section{Hanging}

Death by hanging occurred in 30 cases $(12 \%) ; 87 \%$ of the cases were suicides, 1 case (3\%) was an accidental hanging, and in 3 cases (10\%), the cause of the hanging remained unclear. Most of the cases had occurred during the night (19 cases, 63\%). Only children aged $\geq 9$ years were involved in death by hanging. Twenty cases (67\%) had occurred at home. The postmortem external examination revealed indications of asphyxia in 28 cases (93\%); petechial hemorrhages were found in 20 cases (67\%), and strangulation marks were found in 26 (87\%). Laryngeal or hyoid bone fractures were identified in four cases (13\%) at the ages of 16, 17 (2 cases), and 21 years. 
Table 2 Mechanisms of asphyxia and circumstances of death according to age and sex

Mechanism of asphyxia in different age groups

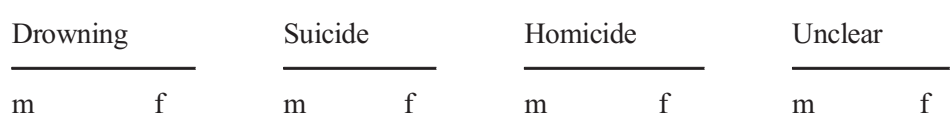

\section{Drowning}

Newborns

Infants

Toddlers

Schoolchildren

Adolescents and young adults

Sum

Total

$\begin{array}{rr}1 & 0 \\ 1 & 2 \\ 19 & 5 \\ 10 & 3 \\ 24 & 6 \\ 55 & 16\end{array}$

$\mathrm{m}$

$\mathrm{m} \quad \mathrm{f}$

Total

Gas inhalation

Newborns

Infants

Schoolchildren

Adolescents and young adults

Sum

Total

0
0
0
0
3
3
4

0
0
0
0
1
1

0
0
1
0
0
1
3

$\begin{array}{ll}1 & 0 \\ 0 & 0 \\ 0 & 0 \\ 1 & 1 \\ 0 & 1 \\ 2 & 2 \\ & 4\end{array}$

2

Aspiration of endogenous fluids

Newborns

Infants

Toddlers

Schoolchildren

Adolescents and young adults

Sum

$\begin{array}{rr}1 & 1 \\ 5 & 5 \\ 7 & 3 \\ 7 & 3 \\ 20 & 12 \\ 32 & \end{array}$

0
0
0
1
1
1

$\begin{array}{ll}0 & 0 \\ 0 & 0 \\ 0 & 0 \\ 0 & 0 \\ 0 & 0 \\ & 0\end{array}$

$\begin{array}{ll}0 & 0 \\ 0 & 0 \\ 0 & 2 \\ 0 & 0 \\ 0 & 2 \\ & 2\end{array}$

Total

$\begin{array}{rr}0 & 1 \\ 1 & 3 \\ 4 & 0 \\ 4 & 5 \\ 8 & 3 \\ 17 & 12\end{array}$

0
0
0
0
1
1
4

$\begin{array}{ll}0 & \\ 0 & \\ 0 & \\ 0 & \\ 3 & \\ 3 & \\ & \end{array}$

$\begin{array}{ll}0 & 0 \\ 0 & 0 \\ 0 & 0 \\ 0 & 0 \\ 0 & 0 \\ 0 & 0 \\ & 0\end{array}$

Hanging

Toddlers

Schoolchildren

Adolescents and young adults

Sum

Total

$\begin{array}{rrr}0 & 1 & 0 \\ 0 & 0 & 5 \\ 0 & 0 & 15 \\ 0 & 1 & 20 \\ 1 & & \end{array}$

Combination of mechanisms of asphyxia

Infants

Toddlers

Schoolchildren

Adolescents and young adults

Sum

Total

$\begin{array}{rllllllll}1 & 0 & 0 & 0 & 1 & 1 & 1 & 0 & 4 \\ 1 & 0 & 0 & 0 & 0 & 0 & 0 & 0 & 1 \\ 0 & 1 & 0 & 0 & 1 & 1 & 0 & 0 & 3 \\ 1 & 0 & 0 & 0 & 0 & 3 & 0 & 0 & 4 \\ 3 & 1 & 0 & 0 & 2 & 5 & 1 & 0 & \\ 4 & & 0 & & 7 & & 1 & & 12\end{array}$

Smothering of respiratory tract

\section{Newborns}

Infants

Toddlers

Schoolchildren

Adolescents and young adults

Sum

Total

Asphyxia during birth

Newborns

Total 
Table 2 (continued)

\begin{tabular}{|c|c|c|c|c|c|c|c|c|c|}
\hline \multirow[t]{2}{*}{ Mechanism of asphyxia in different age groups } & \multicolumn{2}{|c|}{ Drowning } & \multicolumn{2}{|c|}{ Suicide } & \multicolumn{2}{|c|}{ Homicide } & \multicolumn{2}{|c|}{ Unclear } & \multirow[t]{2}{*}{ Tota } \\
\hline & $\mathrm{m}$ & $\mathrm{f}$ & $\mathrm{m}$ & $\mathrm{f}$ & $\mathrm{m}$ & $\mathrm{f}$ & $\mathrm{m}$ & $\mathrm{f}$ & \\
\hline \multicolumn{10}{|l|}{ Manual strangulation } \\
\hline Newborns & 0 & 0 & 0 & 0 & 0 & 2 & 0 & 0 & 2 \\
\hline Schoolchildren & 0 & 0 & 0 & 0 & 3 & 0 & 0 & 0 & 3 \\
\hline Adolescents and young adults & 0 & 0 & 0 & 0 & 1 & 4 & 0 & 0 & 5 \\
\hline Sum & 0 & 0 & 0 & 0 & 4 & 6 & 0 & 0 & \\
\hline Total & 0 & & 0 & & 10 & & 0 & & 10 \\
\hline \multicolumn{10}{|l|}{ Positional asphyxia and constriction } \\
\hline Newborns & 0 & 1 & 0 & 0 & 0 & 0 & 0 & 0 & 1 \\
\hline Infants & 3 & 0 & 0 & 0 & 0 & 0 & 0 & 0 & 3 \\
\hline Toddlers & 1 & 0 & 0 & 0 & 0 & 0 & 0 & 0 & 1 \\
\hline Schoolchildren & 2 & 0 & 0 & 0 & 0 & 0 & 0 & 0 & 2 \\
\hline Adolescents and young adults & 2 & 0 & 0 & 0 & 0 & 0 & 0 & 0 & 2 \\
\hline Sum & 8 & 1 & 0 & 0 & 0 & 0 & 0 & 0 & \\
\hline Total & 9 & & 0 & & 0 & & 0 & & 9 \\
\hline \multicolumn{10}{|l|}{ Aspiration of foreign objects and boluses } \\
\hline Infants & 0 & 1 & 0 & 0 & 0 & 0 & 0 & 0 & 1 \\
\hline Toddlers & 3 & 0 & 0 & 0 & 0 & 0 & 0 & 0 & 3 \\
\hline Schoolchildren & 1 & 0 & 0 & 0 & 0 & 0 & 0 & 0 & 1 \\
\hline Adolescents and young adults & 2 & 0 & 0 & 0 & 0 & 0 & 0 & 0 & 2 \\
\hline Sum & 6 & 1 & 0 & 0 & 0 & 0 & 0 & 0 & \\
\hline Total & 7 & & 0 & & 0 & & 0 & & 7 \\
\hline \multicolumn{10}{|l|}{ Ligature strangulation } \\
\hline Toddlers & 1 & 0 & 0 & 0 & 0 & 1 & 0 & 0 & 2 \\
\hline Schoolchildren & 0 & 0 & 0 & 0 & 0 & 2 & 0 & 0 & 2 \\
\hline Adolescents and young adults & 0 & 0 & 0 & 0 & 1 & 1 & 0 & 0 & 2 \\
\hline Sum & 1 & 0 & 0 & 0 & 1 & 4 & 0 & 0 & \\
\hline Total & 1 & & 0 & & 5 & & 0 & & 6 \\
\hline \multicolumn{10}{|l|}{ Other mechanisms of strangulation } \\
\hline Toddlers & 0 & 1 & 0 & 0 & 0 & 0 & 0 & 0 & 1 \\
\hline Adolescents and young adults & 1 & 1 & 0 & 0 & 0 & 0 & 0 & 0 & 2 \\
\hline Sum & 0 & 2 & 0 & 0 & 0 & 0 & 0 & 0 & \\
\hline Total & 3 & & 0 & & 0 & & 0 & & 3 \\
\hline Sum total & 119 & 49 & 26 & 10 & 13 & 19 & 9 & 4 & \\
\hline Grand total & 168 & & 36 & & 32 & & 13 & & 249 \\
\hline
\end{tabular}

\section{Combined mechanisms of asphyxia}

The following combinations of asphyxia mechanisms occurred among 12 cases (5\%): mechanical and ligature strangulation $(n=2)$, neck compression and smothering of the respiratory tract $(n=2)$, constriction and smothering of the respiratory tract $(n=2)$, drowning and carbon monoxide poisoning $(n=2)$, drowning and manual strangulation $(n=1)$, drowning and smothering of the respiratory tracts $(n=1)$, aspiration of endogenous fluids and manual strangulation $(n=$ $1)$, and neck and chest compression $(n=1)$.

\section{Smothering of the respiratory tract}

Smothering of the respiratory tract was the mechanism of asphyxia in 10 cases (4\%). One case was a suicide in which a 21-year-old man had suffocated himself by putting a plastic bag over his head. Another case involved the accidental death of a 10-month-old child under a bed cover while asleep. Indications of asphyxia were found during the postmortem external examination in seven cases (70\%), and most were in the form of petechial hemorrhages (4 cases, $40 \%$ ). 
Table 3 Findings of asphyxia during the postmortem external examination in different age groups

Age groups Indications of asphyxia in postmortem external examination

\begin{tabular}{lr}
\hline Newborns & $11(58 \%)$ \\
Infants & $15(71 \%)$ \\
Toddlers & $46(88 \%)$ \\
Schoolchildren & $50(89 \%)$ \\
Adolescents and young adults & $92(91 \%)$ \\
Total & $214(86 \%)$
\end{tabular}

\section{Asphyxia during birth}

Death of newborns secondary to asphyxia during birth occurred in 10 cases (4\%). Five cases $(50 \%)$ occurred at the hospital, four (40\%) occurred at home, and one (10\%) occurred at a birthing house. Resuscitation measures were performed in five cases $(50 \%)$. The postmortem external examination revealed indications of asphyxia in three of the children (30\%).

\section{Manual strangulation}

Death solely by manual strangulation occurred in 10 cases (4\%). Nine cases (90\%) showed strangulation marks and nine $(90 \%)$ showed petechial hemorrhages.

\section{Positional asphyxia and constriction}

Positional asphyxia and constriction was the mechanism of asphyxia in nine cases (4\%). All involved accidents. Externally visible indications of asphyxia were identified in eight cases (89\%).

\section{Aspiration of foreign objects}

Aspiration was the mechanism of asphyxia in seven cases (3\%), all of which involved accidents. Resuscitation measures

Table 4 Findings of petechial hemorrhages compared with CPR and non-CPR regarding the different categories of death

\begin{tabular}{|c|c|c|}
\hline \multirow{2}{*}{$\begin{array}{l}\text { Circumstance of } \\
\text { death }\end{array}$} & \multicolumn{2}{|l|}{ Professional CPR } \\
\hline & $\begin{array}{l}\text { No }(n=154) \\
\text { Findings of petechial } \\
\text { hemorrhages }\end{array}$ & $\begin{array}{l}\text { Yes }(n=95) \\
\text { Findings of petechial } \\
\text { hemorrhages }\end{array}$ \\
\hline Accident & 20 & 26 \\
\hline Suicide & 13 & 5 \\
\hline Homicide & 23 & 0 \\
\hline Unclear & 4 & 1 \\
\hline Total & $60(39 \%)$ & $32(34 \%)$ \\
\hline
\end{tabular}

had been performed in four cases $(57 \%)$. The postmortem external examination revealed signs of asphyxia in six cases (86\%); petechial hemorrhages were the most frequently found sign (4 cases, $57 \%$ ).

\section{Ligature strangulation}

Ligature strangulation occurred in six cases (2\%), and postmortem external examination showed findings of asphyxia in all cases.

\section{Other mechanisms of asphyxia}

The following additional mechanisms of asphyxia occurred (3 cases, $1 \%$ ): dislocation of a tracheal cannula at home (preexisting medical condition: respiratory distress syndrome), status asthmaticus, and complication during tracheotomy at the hospital (pre-existing medical condition: Duchenne muscular dystrophy with the development of acute pneumonia). The different causes and categories of asphyxia are summarized in Fig. 2.

\section{Discussion}

Asphyxia in children and adolescents is a rare occurrence when comparing the total number of autopsies with the total number of child deaths reported by the German Federal Statistical Office. In the City-state of Hamburg alone, 126 children aged 0-20 years died in 1998 (19,228 total deaths), and 107 children died in 2016 (17,267 total deaths) [8]. However, asphyxia-related deaths are mostly avoidable cases of death and can be averted with appropriate preventive measures [9-11].

The most common causes of asphyxia in this analysis were accidents, and most involved boys. Suicides involved children from school age onward. Boys were also more prevalent in suicides, whereas girls were more often involved in homicides. Hanging was the leading method of suicide. The largest number of asphyxia cases involved adolescents and young adults aged 15-21 years, and most incidents occurred at home with the exception of drowning, which occurred predominantly in public bodies of water. This distribution is consistent with previous publications in studies of non-natural child deaths in Estonia, Canada, Sri Lanka, Turkey, and the USA [12-16].

In our study, deaths by asphyxia occurred during both day and night. In 1993, a study by Flobecker et al. [17] revealed an increase in accident-related asphyxia deaths in children in Sweden during the early morning hours and in the afternoon. Additionally, the literature shows seasonal increases for specific types of asphyxia. In 2006, Azmak [18] evaluated asphyxia-related deaths in all age groups in Turkey and found that most hangings occurred during spring and summer, and that most carbon monoxide poisonings occurred during 
Fig. 1 Cases of drowning by age

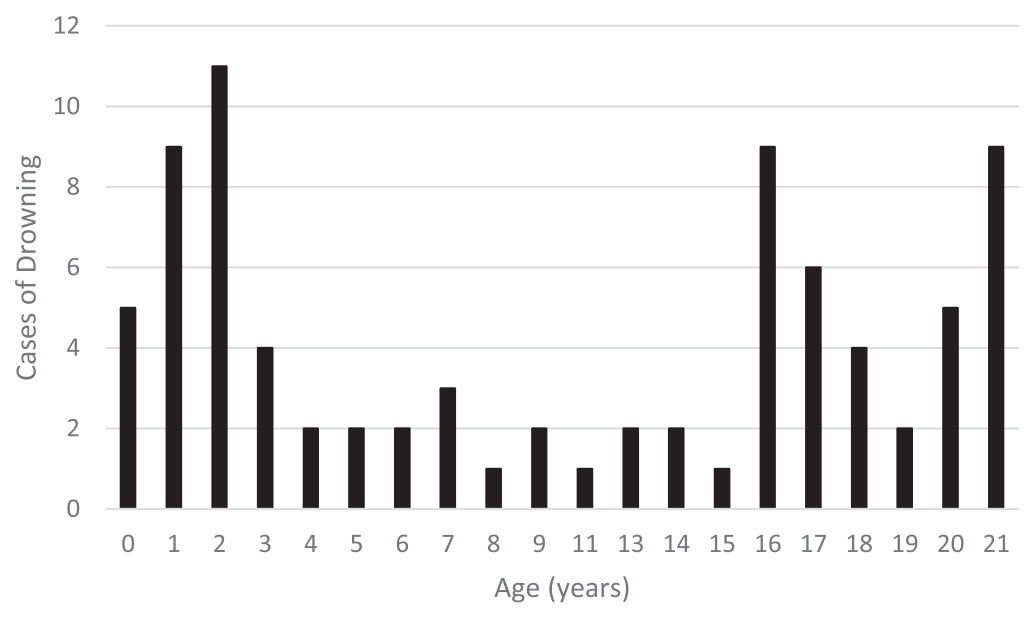

winter. However, in 2014, Bhosle et al. [19] examined hanging in adolescents and found an increased incidence from 2006 to 2009 for no apparent reason. Time of day and seasonal variation in the exposure rate have been shown to play roles in drowning. In two recent Australian studies, Peden et al. [20, 21] identified increased drowning occurrences in children during school vacations and in the bathtub during bathing, from 4:00 PM-6:00 PM.

In 2018, a study by Sasso et al. [22] of asphyxia-related injuries in urgent care facilities in the USA revealed chronic pre-existing medical conditions in $72.8 \%$ of the patients. Patients with a pre-existing medical condition also had a higher risk of dying from an asphyxia-related incident [22]. Pre-existing medical conditions did not play a major role as a concomitant circumstance in cases of asphyxia in children. Predominantly, healthy children were involved in our study, and only those who died by aspiration of endogenous fluids showed an increased incidence of pre-existing medical conditions. This is to be expected because aspiration usually only occurs secondary to other physical impairments.

Our analysis showed that petechial hemorrhages were the most common externally visible finding indicating asphyxia. These appeared most often in children who had died of ligature strangulation, manual strangulation, or hanging. The presence of petechial hemorrhages in cases of strangulation differs vastly in the literature. A 2016 study by Ma et al. [23] of cases of hanging and strangulation in all age categories in China showed that petechial hemorrhages were present in $95 \%$ of hanging cases and in $52 \%$ of strangulation cases. However, in a 2016 study of hanging in Italy, Russo et al. [24] found only conjunctival petechial hemorrhages in $11 \%$ of the cases.

Petechial hemorrhages are caused by venous obstruction in continuous arterial flow. Other than asphyxia, such hemorrhages can be caused by many other conditions such as asthma attacks, status epilepticus, coughing, vomiting, and cardiac massage. Therefore, their sole presence is not clear evidence
Fig. 2 Causes and categories of asphyxia

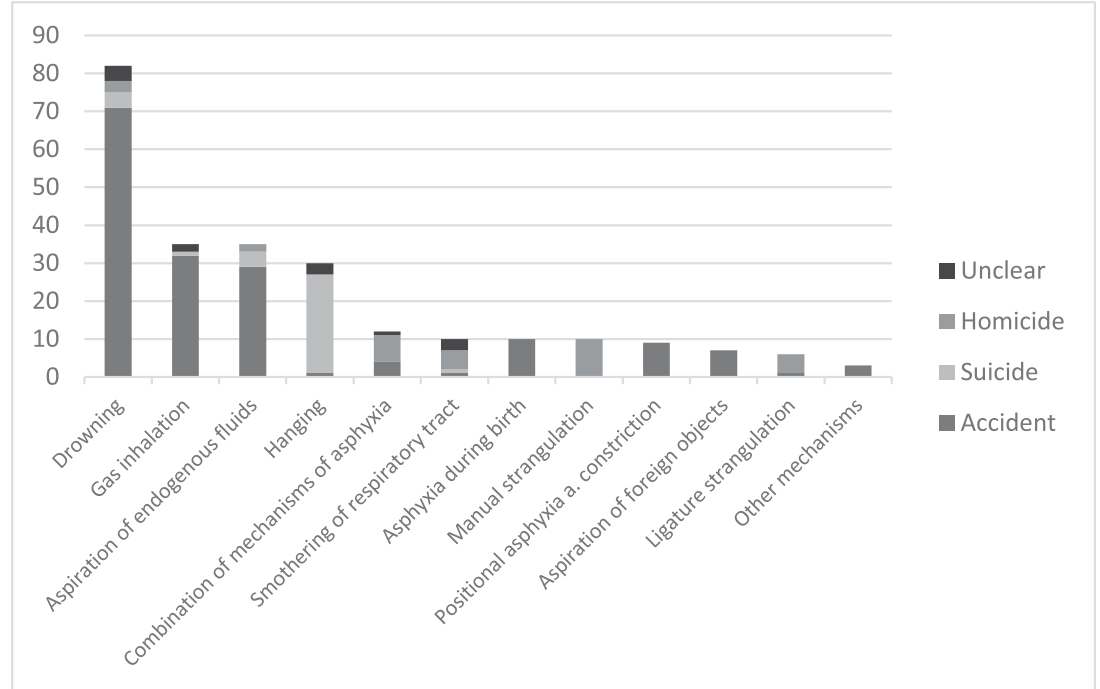


of asphyxia [25-27]. However, when present in conjunction with other findings of asphyxia detected during the autopsy, petechial hemorrhages are useful for distinguishing asphyxiarelated death from SIDS [28]. In our study, there was no higher incidence of petechiae in cases with CPR.

The findings related to asphyxia gathered during autopsy, such as hyperinflated lungs, bleeding beneath organ membranes, and blood stasis in the organs, are also nonspecific. In 2010, Fracasso et al. [29] found hemorrhages causing asphyxia beneath the organ membranes of newborns who had died of asphyxia as well as in newborns who had died of SIDS, sepsis, or respiratory tract infections. Findings of asphyxia may also be completely missing when the attacker has significantly more physical strength than the victim [30].

Our results regarding the verification of asphyxia and the circumstances of death indicate that a postmortem external examination by itself is insufficient. In addition to autopsy and evaluating pre-existing conditions, histological, toxicological, and neuropathological examinations are also useful to achieve the correct diagnosis [31, 32]. However, even with the most meticulous execution of all of these examinations, it is not always possible to clearly differentiate between an asphyxia-related homicide with very few traces and death from internal causes (e.g., SIDS).

This study has several limitations because of its retrospective design. Because the data were gathered from autopsy reports, they are not completely standardized and, thus, are dependent on the relative quality of the examination and documentation. As described by Colville-Ebeling et al. [33] in 2013, the quality of the data is largely dependent on the experience of the medical examiner. The data are not adequate to shed light on a potential dark field of undetected asphyxiarelated cases of death (e.g., external signs of asphyxia are present but no autopsy is performed; however, in our study region, it is highly unlikely that such cases do not undergo a medicolegal autopsy). Because the diagnosis of death caused by asphyxia is sometimes based on external findings, circular reasoning cannot be totally excluded. For example, if injuries on the skin of the neck and petechial hemorrhages on the conjunctiva have led to a diagnosis of manual strangulation, ligature strangulation, or hanging, these diagnoses will be found on a regular basis in cases of this type of death.

In the present study, lack of information or only estimated values were often obtained regarding, for example, the time of occurrence or time of death, and regarding the children's ability to swim. Regarding the presence of a chaperone, we included cases in which a chaperone had been in the same building or within shouting distance, as had occurred in care facilities such as childcare facilities or schools. However, when a chaperone is present, only direct supervision is a true preventive factor $[9,17]$.

Finally, the statistical power of our data is limited by the relatively small number of cases. However, the specific objective of this study was individual case assessment and systematic presentation to facilitate categorizing cases into accidents, suicides, or homicides. This is the only way to identify hazardous situations and provide recommendations for preventive measures.

Acknowledgments Open Access funding provided by Projekt DEAL. We thank Angela Morben, DVM, ELS, from Edanz Group (www. edanzediting.com/ac), for editing a draft of this manuscript.

\section{Compliance with ethical standards}

Conflict of interest The authors declare that they have no conflict of interest.

Ethical approval All procedures performed in studies involving human participants were in accordance with ethical standards of the institutional and/ or national research committee and with the 1964 Helsinki declaration and its later amendments or comparable ethical standards.

Informed consent Informed consent was waived due to the retrospective nature of this study.

Open Access This article is licensed under a Creative Commons Attribution 4.0 International License, which permits use, sharing, adaptation, distribution and reproduction in any medium or format, as long as you give appropriate credit to the original author(s) and the source, provide a link to the Creative Commons licence, and indicate if changes were made. The images or other third party material in this article are included in the article's Creative Commons licence, unless indicated otherwise in a credit line to the material. If material is not included in the article's Creative Commons licence and your intended use is not permitted by statutory regulation or exceeds the permitted use, you will need to obtain permission directly from the copyright holder. To view a copy of this licence, visit http://creativecommons.org/licenses/by/4.0/.

\section{References}

1. Byard R (2011) Issues in the classification and pathological diagnosis of asphyxia. Aust J Forensic Sci 43(1):27-38

2. Byard RW, Jensen LL (2007) Fatal asphyxial episodes in the very young: classification and diagnostic issues. Forensic Sci Med Pathol 3(3):177-181

3. Sauvageau A, Boghossian E (2010) Classification of asphyxia: the need for standardization. J Forensic Sci 55(5):1259-1267

4. Elsässer G. Unfälle, Gewalt, Selbstverletzung bei Kindern und Jugendlichen 2017. Ergebnisse der amtlichen Statistik zum Verletzungsgeschehen 2014.: Statistisches Bundesamt; 2017

5. Meyer FS, Trubner K, Schopfer J, Zimmer G, Schmidt E, Puschel $\mathrm{K}$ et al (2012) Accidental mechanical asphyxia of children in Germany between 2000 and 2008. Int J Legal Med 126(5):765-771

6. Byard RW (2000) Accidental childhood death and the role of the pathologist. Pediatr Dev Pathol 3(5):405-418

7. Randall B, Donelan K, Koponen M, Sens MA, Krous HF (2012) Application of a classification system focusing on potential asphyxia for cases of sudden unexpected infant death. Forensic Sci Med Pathol 8(1):34-39

8. Statistische Ämter des Bundes und der Länder. Gestorbene nach Geschlecht, Nationalität und Altersgruppen - Jahressumme - 
regionale Tiefe: Kreise und krfr. Städte. 2019 https://www. regionalstatistik.de/genesis/online/data. Accessed 10 April 2019

9. Brenner RA (2003) Prevention of drowning in infants, children, and adolescents. Pediatrics. 112(2):440-445

10. Rimsza ME, Schackner RA, Bowen KA, Marshall W (2002) Can child deaths be prevented? The Arizona Child Fatality Review Program experience. Pediatrics. 110(1 Pt 1):e11

11. Committee on Injury, Violence, and Poison Prevention (2010) Prevention of choking among children. Pediatrics. 125(3):601-607

12. Vali M, Lang K, Soonets R, Talumae M, Grjibovski AM (2007) Childhood deaths from external causes in Estonia, 2001-2005. BMC Public Health 7:158

13. Herath JC, Kalikias S, Phillips SM, Del Bigio MR (2014) Traumatic and other non-natural childhood deaths in Manitoba, Canada: a retrospective autopsy analysis (1989-2010). Can J Public Health 105(2):e103-e108

14. Kitulwatte ID, Edirisinghe PA (2014) Study on unnatural childhood deaths presented to North Colombo Teaching Hospital, Sri Lanka. Med Sci Law 54(2):74-77

15. Canturk N, Es Iyok B, Ozkara E, Canturk G, Bulent Ozata A, Fatih YM (2007) Medico-legal child deaths in Istanbul: data from the Morgue Department. Pediatr Int 49(1):88-93

16. Okoye CN, Okoye MI (2011) Forensic epidemiology of childhood deaths in Nebraska, USA. J Forensic Legal Med 18(8):366-374

17. Flobecker P, Ottosson J, Johansson L, Hietala MA, Gezelius C, Eriksson A (1993) Accidental deaths from asphyxia. A 10-year retrospective study from Sweden. Am J Forensic Med Pathol 14(1):74-79

18. Azmak D (2006) Asphyxial deaths: a retrospective study and review of the literature. Am J Forensic Med Pathol 27(2):134-144

19. Bhosle SH, Zanjad NP, Dake MD, Godbole HV (2015) Deaths due to hanging among adolescents - a 10-year retrospective study. J Forensic Legal Med 29:30-33

20. Peden AE, Barnsley PD, Queiroga AC (2019) The association between school holidays and unintentional fatal drowning among children and adolescents aged 5-17 years. J Paediatr Child Health 55(5):533-538

21. Peden AE, Franklin RC, Pearn JH (2018) Unintentional fatal child drowning in the bath: a 12-year Australian review (2002-2014). J Paediatr Child Health 54(2):153-159
22. Sasso R, Bachir R, El Sayed M (2018) Suffocation injuries in the United States: patient characteristics and factors associated with mortality. West J Emerg Med 19(4):707-714

23. Ma J, Jing H, Zeng Y, Tao L, Yang Y, Ma K et al (2016) Retrospective analysis of 319 hanging and strangulation cases between 2001 and 2014 in Shanghai. West J Emerg Med 42:19-24

24. Russo MC, Verzeletti A, Piras M, De Ferrari F (2016) Hanging deaths: a retrospective study regarding 260 cases. Am J Forensic Med Pathol 37(3):141-145

25. Ely SF, Hirsch CS (2000) Asphyxial deaths and petechiae: a review. J Forensic Sci 45(6):1274-1277

26. Hashimoto Y, Moriya F, Furumiya J (2007) Forensic aspects of complications resulting from cardiopulmonary resuscitation. Leg Med (Tokyo) 9(2):94-99

27. Maxeiner H, Jekat R (2010) Resuscitation and conjunctival petechial hemorrhages. J Forensic Legal Med 17(2):87-91

28. Betz P, Hausmann R, Eisenmenger W (1998) A contribution to a possible differentiation between SIDS and asphyxiation. Forensic Sci Int 91(2):147-152

29. Fracasso T, Vennemann M, Klocker M, Bajanowski T, Brinkmann $\mathrm{B}$, Pfeiffer $\mathrm{H}$ et al (2011) Petechial bleedings in sudden infant death. Int J Legal Med 125(2):205-210

30. Puschel K, Turk E, Lach H (2004) Asphyxia-related deaths. Forensic Sci Int 144(2-3):211-214

31. Bajanowski T, Vennemann M, Bohnert M, Rauch E, Brinkmann B, Mitchell EA (2005) Unnatural causes of sudden unexpected deaths initially thought to be sudden infant death syndrome. Int J Legal Med 119(4):213-216

32. Delmonte C, Capelozzi VL (2001) Morphologic determinants of asphyxia in lungs: a semiquantitative study in forensic autopsies. Am J Forensic Med Pathol 22(2):139-149

33. Colville-Ebeling B, Freeman M, Banner J, Lynnerup N (2014) Autopsy practice in forensic pathology-evidence-based or experience-based? A review of autopsies performed on victims of traumatic asphyxia in a mass disaster. J Forensic Legal Med 22:33-36

Publisher's note Springer Nature remains neutral with regard to jurisdictional claims in published maps and institutional affiliations. 